\title{
GETTING TO THE
}

\section{ROOT OF PINE DECLINE}

\author{
DR LORI ECKHARDT IS INVESTIGATING THE CAUSE OF A DEADLY ROOT \\ DISEASE - KNOWN AS PINE DECLINE - IN THE SOUTHEASTERN UNITED STATES. \\ USING HYPERSPECTRAL INTERFEROMETRY TO LOCATE FUNGAL SPORES ON \\ BARK BEETLES, HER WORK IS HELPING US TO BETTER UNDERSTAND HOW TO \\ MANAGE AND PROTECT PINE PLANTATIONS AND FORESTS
}

\section{WHAT IS HYPERSPECTRAL}

\section{INTERFEROMETRY?}

When we look at a rainbow, the colours we see are just a section of the electromagnetic radiation spectrum. There is, in fact, a lot more to this spectrum: infrared, ultraviolet light, X-rays, microwaves (not ovens!) and radiowaves. Hyperspectral imaging allows scientists to look at objects using the vast proportion of the electromagnetic spectrum, beyond what we would normally see with the human eye.

Objects (including insects and fungi) leave unique 'fingerprints' in the electromagnetic spectrum known as spectral signatures. And it is these signatures that allow scientists to identify the object. For example, geologists use a spectral signature for oil to find new oil fields.

Lori has been using this tool to look for ophiostomatoid (o'fi'os-tō-mä'toi'd) fungi spores on bark beetles, which has exciting prospects for discovering other insects that carry harmful fungi.

Whether it's furniture, flooring, toilet roll or paper, many items in our homes are made from pine. Pine trees are native to the Northern Hemisphere and are among the most important trees for timber and other industrial and household products. One region that is heavily reliant on pine is southeastern US. Here, pine trees are grown in plantations, bringing in billions of dollars to the local and national economy, and creating millions of jobs. But, a deadly root disease is taking hold, endangering pine trees that are already under a lot of stress, as well as the industries that rely on this vital wood crop.

Based at Auburn University in Alabama, USA, Dr Lori Eckhardt is an entomologist and forest pathologist. This means she studies insects (entomology) and diseases affecting a forest ecosystem (forest pathology). She is looking into the reasons behind pine decline, which has become a major issue for southeastern US in the last 20 years. Focusing particularly on the bark beetle and ophiostomatoid (o'fi'os-tōmä'toi'd) fungi, Lori's aim is to find new ways to manage and prevent this root disease.

\section{WHAT IS PINE DECLINE?}

Pine decline is a complex disease. This means that the infection is a result of many interacting factors such as insects, fungi, soil type and climate. Trees suffering from pine decline show signs of bark beetles and ophiostomatoid fungi in their deteriorating roots.

\section{IS PINE DECLINE CAUSING TREES TO DIE IN LARGE NUMBERS IN} SOUTHEASTERN US?

It's not known whether pine decline is the main factor responsible for the death of pine trees because there are so many stressors involved, including pollution, changes in weather patterns and temperature, urbanisation, insect pests, fungal pests and others.
One stressor, for example, is the introduction of non-native pests. Insects like gypsy moth or emerald borer weren't originally from the US, but they were unintentionally transported to the country through human travel and international trade. These insects have managed to adapt to their new environment and cause devastation to trees and plants that haven't had the time to evolve and develop full resistance to them. "Non-native insects can wipe out entire species of trees and plants, altering ecosystems and affecting wildlife," says Lori.

\section{WHAT DO WE KNOW ABOUT BARK} BEETLES?

Although often described as 'pests', rootfeeding bark beetles can provide great benefits such as nutrient cycling to forests. Similar to a water cycle, the nutrient cycle is the movement of nutrients such as calcium, potassium and magnesium within an ecosystem. The problem is, root-feeding bark beetles can become aggressive in large numbers and, as their name suggests, will attack the bark, roots and lower trunk of trees.

Due to acid rain, industrialisation, toxic gases from vehicles and all the factors mentioned above, pine trees are under a great deal of stress, and are therefore more susceptible to bark beetle invasion. Not only that, but the beetles' symbiotic relationship with ophiostomatoid fungi or 'blue stain fungi' can wreak havoc on stressed pine trees. The fungi are known as blue stain fungi because they leave blue stains in the wood, making it less viable for the wood industry. 



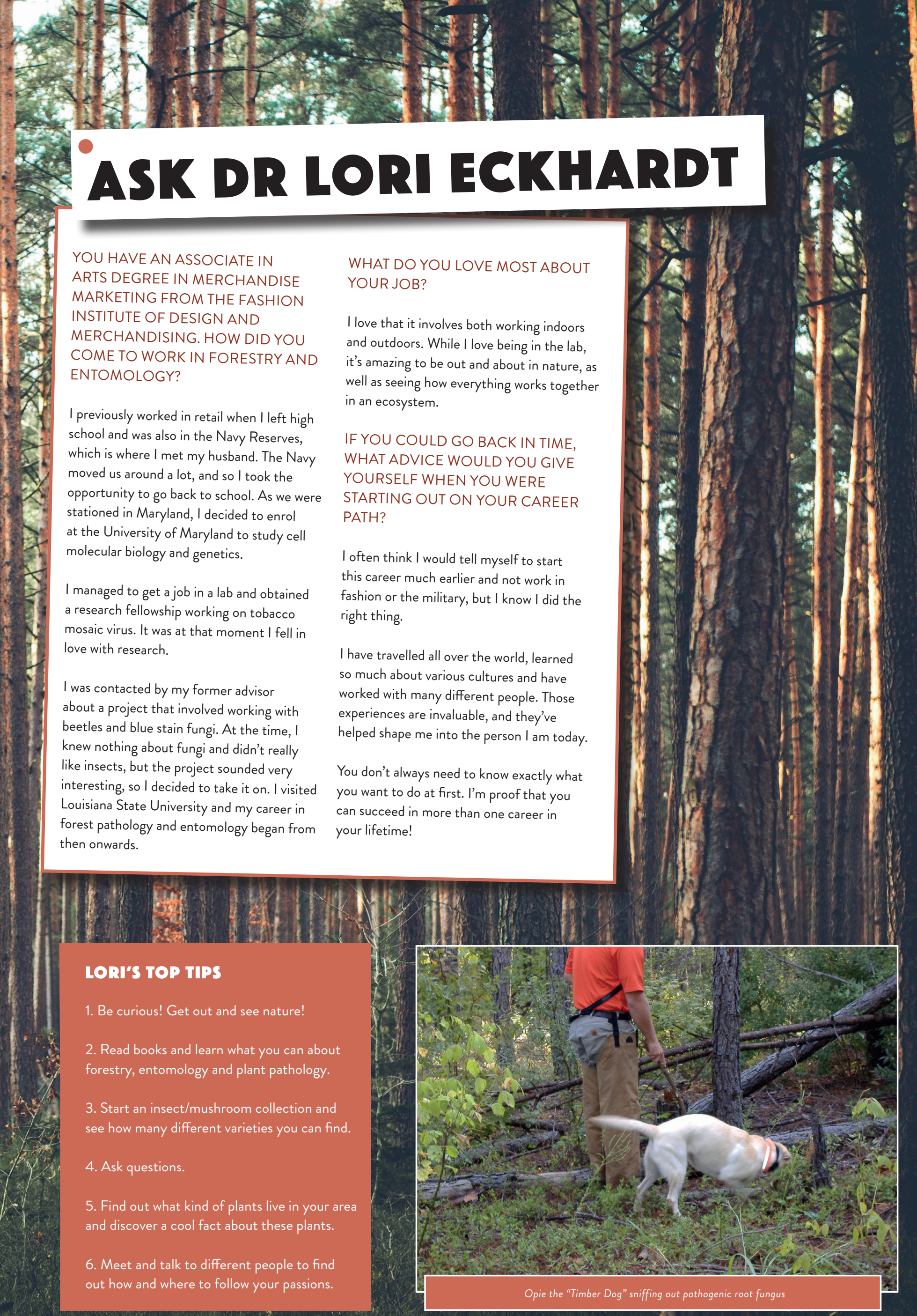

